\title{
Visual evoked potentials after retrobulbar or periocular anaesthesia
}

\author{
Auli Ropo, Pekka Ruusuvaara, Kirsi Setälä
}

\begin{abstract}
The effect of the local anaesthetic agent, etidocaine, on the optic nerve function was examined at regional ophthalmic anaesthesia. Visual evoked potential (VEP) was recorded before and 15 minutes after injection of the anaesthetic agent in 19 patients scheduled for elective cataract surgery (seven retrobulbar and 12 periocular). Both the anaesthetised that is, the eye to be operated on - and the fellow eye were examined. In the retrobulbar group, two patients displayed non-recordable VEPs while one had virtually non-detectable waves following the anaesthesia. In two retrobulbarly anaesthetised eyes, later peaks were unidentifiable while two other eyes had decreased amplitudes. In the periocular group, in nine patients, there was no clearcut effect on VEP resulting from the anaesthetic. In three patients of this group mild changes in the anaesthetised eyes were found. The differences in the effect of retrobulbarly or periocularly injected anaesthetics on VEP are probably due to the different concentration of the anaesthetic agent around the optic nerve. (Brf Ophthalmol 1992; 76: 541-544)
\end{abstract}

Periocular anaesthesia is an alternative method to the retrobulbar technique for providing local blockade in eye surgery. In the periocular method, the extraconal position of the injection needle is reported to be accompanied by a lower incidence of serious complications. ${ }^{12}$ On the other hand, life threatening respiratory arrest ${ }^{34}$ and unilateral or bilateral amaurosis due to toxic or mechanical injury to the optic nerve, although rare, are complications of the retrobulbar technique. ${ }^{567}$ Although some deny that periocular anaesthesia could result in black-out of vision, ${ }^{1}$ temporary visual loss caused by the anaesthetic agent has been described both with the retrobulbar and the periocular technique..$^{8-13}$ The addition of hyaluronidase to the local anaesthetic solution is believed to increase the transient loss of vision ${ }^{14}$ during retrobulbar anaesthesia.

The visual evoked potential (VEP) is an electrical response of the visual cortex to an appropriate visual stimulus. Normal individuals exhibit a variety of complex waveforms arising from flash VEP. In spite of this a unilateral abnormality is detectable with this method. ${ }^{15} \mathrm{~A}$ patient presenting with a cataract alone will demonstrate an intact VEP response. If, however, the cataract is coexistent with - for example, macular degeneration or optic atrophy, then an abnormal VEP becomes evident. ${ }^{16}$ Changes in VEP have earlier been detected during general anaesthesia. ${ }^{17} 18$ In regional anaesthesia of the eye temporary visual blocks and abnormal VEPs have earlier been reported in a few patients following retrobulbar block. ${ }^{1920}$ On the other hand, in a recent study. the VEPs of three patients after peribulbar anaesthesia showed no significant changes. ${ }^{21}$

The purpose of the present study was to compare the effect of a local anaesthetic drug injected either by periocular or retrobulbar route, on VEP.

\section{Patients and methods}

A total of 19 patients scheduled to undergo elective cataract surgery were divided into two groups. Lorazepam (Temesta, Wyeth, USA) 1-2 $\mathrm{mg}$, was given as an oral predmedication 3 hours prior to the administration of regional anaesthesia. One group of seven patients was given a retrobulbar anaesthesia with a semisharp $35 \mathrm{~mm}$ needle (2R2, Luer Lock). The other group (12 patients) was given one periocular, inferolateral injection with a sharp 25 gauge, $25 \mathrm{~mm}$ needle (Terumo, Belgium). The volume of the injections was $3 \mathrm{ml}$ with the retrobulbar and $4 \mathrm{ml}$ with the periocular technique. The anaesthetic solution in both groups was prepared by mixing $20 \mathrm{ml}$ of etidocaine (Duranest, Suomen Astra, Sweden), $15 \mathrm{mg} / \mathrm{ml}$, with $1 \mathrm{ml}$ of hyaluronidase, $150 \mathrm{IU} / \mathrm{ml}$ (Hyason, Organon, Holland). One patient in the retrobulbar group required a further injection of $2 \mathrm{ml}$ because of insufficient akinesia. In the periocular group, four supplemental injections of $3 \mathrm{ml}$ were given superonasally. For orbicular
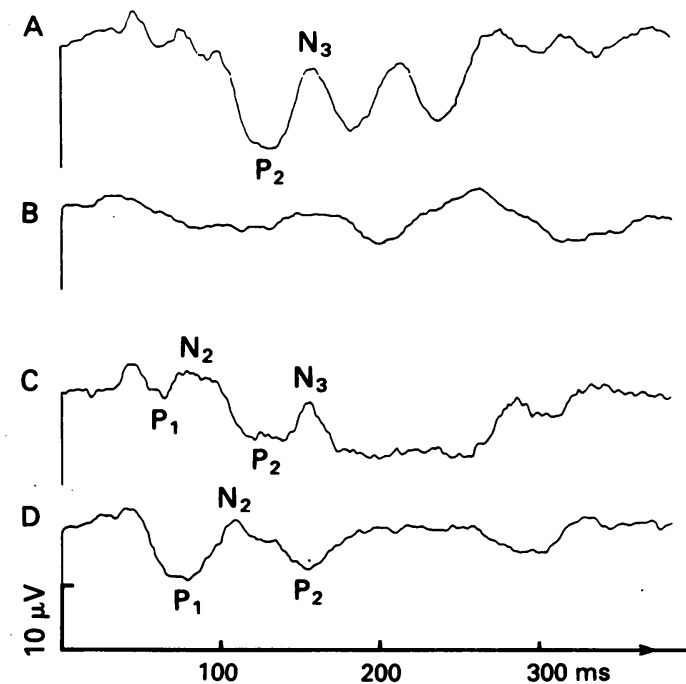

Figure 1 Visual evoked potential (VEP) before $(A)$ and after $(B)$ retrobulbar anaesthesia. VEP is not recordable after the anaesthesia. The fellow, non-anaesthetised eye shows only the anaesthesia. The fellow, non-anaesthetised eye shows only
slightly increased latencies $(D)$ when compared with the preanaesthesia situation $(C)$. 

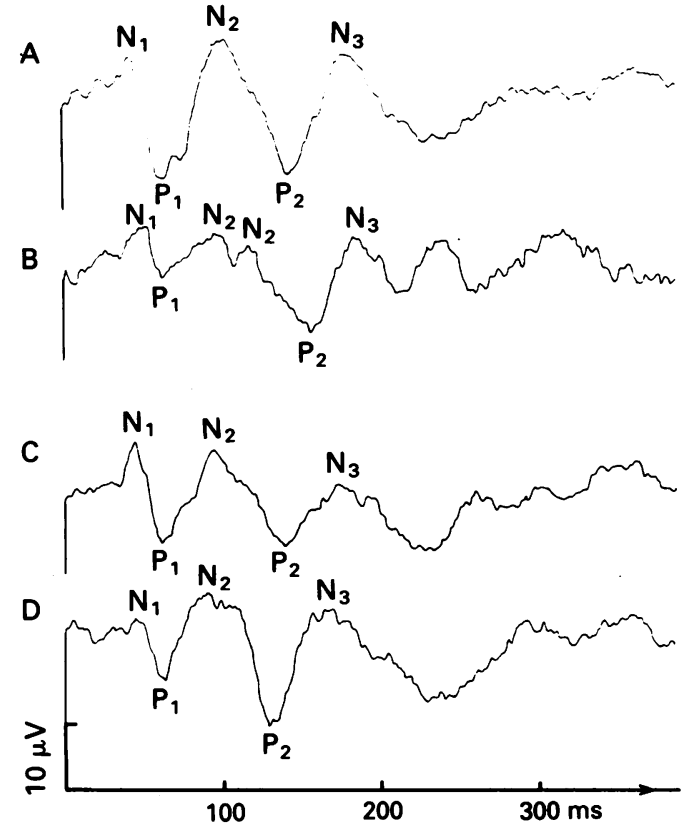

Figure 2 Reduced amplitudes after retrobulbar anaesthesia (B) compared with the pre-anaesthesia responses $(A)$. No clear changes are seen in the fellow eye $(C$ and $D)$.

akinesia, $5 \mathrm{ml}$ of the anaesthetic mixture were injected subcutaneously into eyelids in all patients.

VEPs and subjective light perception with a penlight were examined from both eyes 1 to 3 days prior to surgery. After a dark adaptation of 15 minutes, light flashes of $0.2 \mathrm{~J}$ at $1 \mathrm{flash} / \mathrm{s}$ were delivered from a Kaiser photostimulator which was placed $20 \mathrm{~cm}$ in front of the face. While the one eye was being stimulated, the other was kept covered with a tight patch. The recording electrode was placed in the midline, $2 \mathrm{~cm}$ above the inion $\left(\mathrm{O}_{\mathrm{o}}\right.$ in the international $10-20$ system). A common earlobe electrode was used for reference. The response was amplified via an Elema Mingograph. One hundred responses per eye were averaged on-line by a Nokia Channel Analyser LP4840 and recorded with a Houston $\mathrm{XY}$ writer. After the regional block was completed, both eyes with dilated pupils were covered. A pressure reducer device (Autopressor, Storz, Germany) was applied to the anaesthetised eye, while the fellow eye was covered with a black patch. When an adaptation time of 15 minutes had passed, subjective light perception was examined and VEP was recorded again from both eyes.

The peaks were identified using $\mathrm{N}$ and $\mathrm{P}$ for symbols, $\mathrm{N}$ being a negative (upward) and $\mathrm{P}$ a positive (downward) deflection from the baseline, and put in numerical order according to Harding. ${ }^{22}$ The latencies (ms) and peak-to-peak amplitudes of $(\mu \mathrm{V})$ of waves $P_{1}, N_{2}$, and $P_{2}$ were measured from the XY recordings by a neuroophthalmologist unaware of which eye had been treated and to which group the patients belonged.

\section{Results}

The mean age of the patients in the retrobulbar group was 74.6 (SD 4.7) and in the periocular group $74 \cdot 1(\mathrm{SD} 2 \cdot 4)$ years.

\section{RETROBULBAR GROUP}

In the retrobulbar group subjective light perception was normal in five patients 15 minutes after the injection of the anaesthetic agent. One patient in this group had only temporal projection left while a second had lost nasal projection.

Following retrobulbar anaesthesia, the VEPs of two patients were non-recordable although the pre-anaesthesia VEPs were present (Fig 1). One of these patients had a normal subjective light perception while the other had lost her nasal projection. The pre-anaesthesia visual acuities of these respective patients were 0.2 and light perception. The fellow eyes of these patients displayed smaller changes. In the first patient the latencies increased $\left(P_{1}\right.$ by $14, N_{2}$ by 25 , and $P_{2}$ by $27 \mathrm{~ms}$ ) while in the second patient only the amplitudes changed (decrease of 6-7 $\mu \mathrm{V}$ ). The patient with only temporal projection remaining had hardly recordable responses in VEP showing only waveform $\mathrm{N}_{1}$ with disappearance of the later waverforms. No changes were found in the fellow eye of this patient.

The late responses disappeared in two patients: in the first, $P_{2}$ was no longer identifiable after anaesthesia, while in the second the same was true with $N_{2}$ and $P_{2}$. The latency of $P_{1}$ of the second patient increased by $13 \mathrm{~ms}$. The fellow eyes of these two patients displayed mildly increased latencies of $P_{2}(11$ and $22 \mathrm{~ms})$. In the final two patients, the amplitudes were reduced (Fig 2) and the shape of the waveform $\mathrm{N}_{2}$ changed from $N$ to $W$ but no changes were found in the latencies. The responses of the fellow eyes did not change.

The two non-recordable VEPs were recorded anew during a check-up visit and were found to be similar to the pre-anaesthesia recordings.

\section{PERIOCULAR GROUP}

All patients belonging to the periocular group had normal light perception after the anaesthesia.

After periocular anaesthesia, no patients demonstrated non-recordable VEPs. When
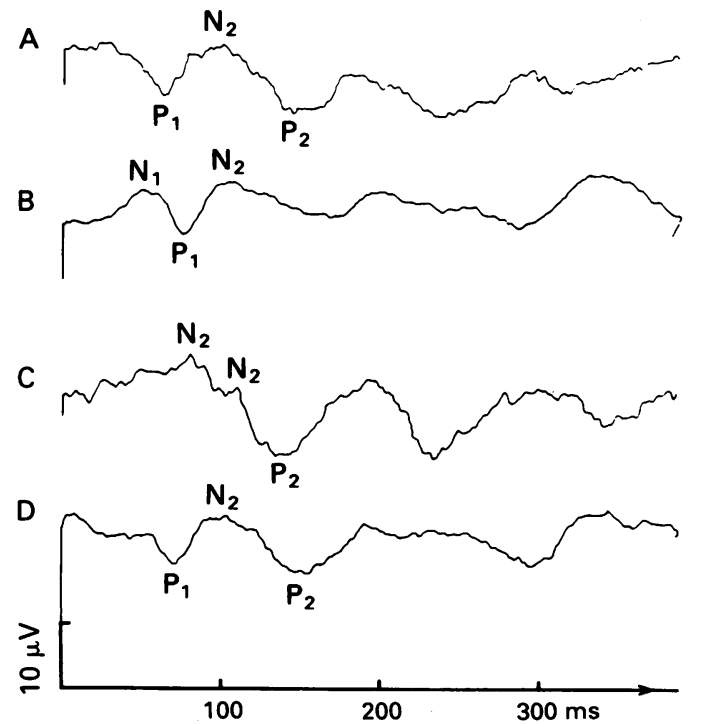

Figure 3 Mild changes after periocular anaesthesia in the anaesthetised eye ( $A$ before, $B$ after) as well as in the fellow eye $(C$ before, $D$ after). The late latencies are increased while the amplitudes are decreased. 
$\mathrm{N}_{2}$
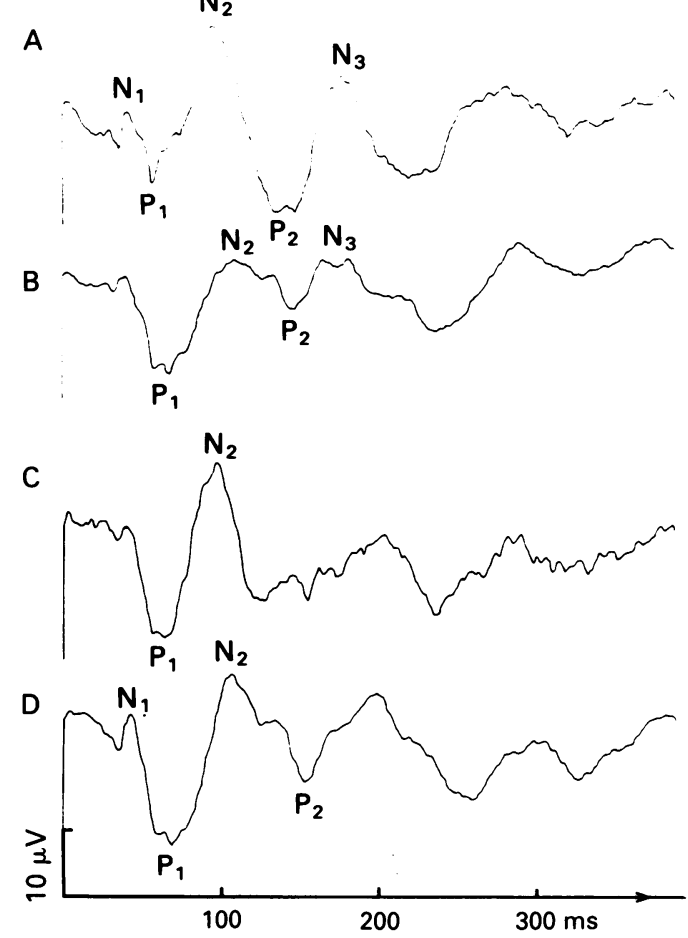

Figure 4 Compared with the pre-anaesthesia situation $(A)$, the latencies are increased and the amplitudes decreased after periocular anaesthesia $(B)$. There are no clear changes in the fellow eye ( $C$ and $D)$

compared with the pre-anaesthesia VEPs, both eyes of eight patients displayed mildly increased latencies and reduced amplitudes (Fig 3). The latencies of $P_{1}, N_{2}$, and $P_{2}$ increased by $6 \mathrm{~ms}$ (median) in the anaesthetised eyes while the increases in the fellow eyes were 4,16 , and $18 \mathrm{~ms}$ (median). The amplitudes of $\mathrm{P}_{1}, \mathrm{~N}_{2}$, and $\mathrm{P}_{2}$ reduced by 0,1 , and $3 \mu \mathrm{V}$ (median) in the anaesthetised eyes and by 1,1 , and $2 \mu \mathrm{V}$ (median) in the fellow eyes.

Of the remaining four patients three manifested with reduced amplitudes $\left(P_{1}\right.$ by 1,4 , and 5 $\mu \mathrm{V} ; \mathrm{N}_{2}$ by 4,20 , and $11 \mu \mathrm{V} ; \mathrm{P}_{2}$ by 3,12 , and 3 $\mu \mathrm{V})$ in the anaesthetised eyes with no clear changes in the latencies. No changes were found in the VEPs of the fellow eyes of these three patients (Fig 4). In the last patient of this group, no changes were found in the anaesthetised eye while mild increases in the latencies were detected in the fellow eye.

\section{Discussion}

In this study the waves of VEPs were classified according to Harding. ${ }^{23}$ Wave $\mathrm{P}_{1}$ corresponds to a positive peak appearing at around $60 \mathrm{~ms}\left(\mathrm{P}_{60}\right)$, $\mathrm{N}_{2}$ to a negative peak at about $75 \mathrm{~ms}\left(\mathrm{~N}_{75}\right)$, and $P_{2}$ to a positive peak at about $100 \mathrm{~ms}\left(P_{100}\right)$. However, normal values for VEP latencies are dependent on the patient's age and the intensity of the flash. For example, the latency of $P_{2}$ increases with age from 114.5 (SD 9.8) (10-19 years) to $134 \cdot 3$ (SD 12.7) (70-79 years) $\mu \mathrm{V} / \mathrm{s}^{23}$

The study reveals that local anaesthetic agents can alter electrical activity of the optic nerve. Periocular anaesthesia (extraconal injection) seemed to have only a slight or no effect on VEP. On the other hand there were obvious changes in
VEPs following the retrobulbar (intraconal) injection. A rapid diffusion of the anaesthetic agent from the extraconal to the intraconal space occurs in the periocular technique while the reverse can be seen in the retrobulbar method. ${ }^{24}$ When using the retrobulbar technique the concentration of the anaesthetic agent becomes very high around the optic nerve. In the periocular technique however the optic nerve is not reached by all of the injected anaesthetic. The results here support an earlier observation that a transient conduction block is probably caused by the absorption of the anaesthetic agent. ${ }^{20}$

Subjective light perception did not correlate with the total loss of the VEP responses in the retrobulbar group. Unfortunately, the afferent pupillary defect could not be examined because the fellow eye served as control. However in an earlier study, despite the afferent pupillary defect after retrobulbar anaesthesia, $75 \%$ of the patients could detect the operating instruments. ${ }^{12}$ In the present study all the patients of the periocular group had normal light perception following the injection. This is in contrast to an earlier result ${ }^{11}$ in which $22 \%$ of patients lost their light perception after their periocular blockade. This might be partially explained by the larger volume of the anaesthetic agent used in that previous study. Subjective light perception in a premedicated patient may also be subject to errors in cooperation.

Premedication and its effect on the electrical activity of the brain might also explain why the VEPs recorded from the fellow eye in 13 of 19 patients showed mild changes. This was especially noticed in the periocular group where eight patients displayed mild, but similar, changes in both the anaesthetised and the fellow eye.

We omitted statistical analysis because of the different size of the study groups. Statistical analysis would also have become unreliable because in three patients most of the waves were unidentifiable after retrobulbar anaesthesia. As it was noticed that retrobulbar anaesthesia with a long needle caused great changes in VEPs the use of that particular method was discontinued.

This study suggests that periocular anaesthesia with a $25 \mathrm{~mm}$ needle may be safer for the optic nerve function than retrobulbar anaesthesia with a $35 \mathrm{~mm}$ needle. Though the effect of the anaesthetic on the optic nerve conduction is transient it may be deleterious in some compromised (for example, ischaemic, glaucomatous) eyes. Because of this safety factor and the equally good akinesia compared with the akinesia after the retrobulbar technique, ${ }^{25}{ }^{26}$ the periocular method is a good alternative to retrobulbar anaesthesia in eye surgery.

We are grateful to staff.nurse Lea Riekki for recording the VEPs. This study was supported by The Eye Foundation and The Paulo Foundation, Helsinki, Finland.

1 Davis DB, Mandel MR. Posterior peribulbar anesthesia: an alternative to retrobulbar anesthesia. Impl Ophthalmol 1988, 2: $154-6$.

2 Bloomberg LB. Administration of periocular anesthesia. $\mathcal{F}$ Cataract Refract Surg 1986; 12: 677-9.

3 Ruusuvaara P, Setälä K, Tarkkanen A. Respiratory arrest after retrobulbar block. Acta Ophthalmol $(K b h)$ 1988; 66 223-5.

4 Javitt JC, Addiego RA, Friedberg HL, Libonati MM, Leahy 
JJ. Brain stem anaesthesia after retrobulbar block. Ophthalmology 1987; 94: 718-23.

5 Pautler SE, Grizzard WS, Thompson LN, Wing GL. Blindness from retrobulbar injection into the optic nerve. Ophthalmol from retrobulbar injection 1986; 17: 334-7.

6 Friedberg HL, Kline OR. Contralateral amaurosis after retrobulbar injection. $A m \mathcal{f}$

7 Follette JW, Locascio JA. Bilateral amaurosis following unilateral retrobulbar block.

8 Doden W, Makabe R. Transitorischer visusverlust nach retrobulbärer anästhesie. 3 Kongr europ Ges Ophthal, Amsterdam. Ophthalmologica 1969; 158 (Suppl): 441-7.

9 Kruger KT. Transitorische Erblindung nach retrobulbar Anästhesie. Klin Monatsbl Augenheilkd 1966; 149: 523-6.

10 Carroll FD, de Roetth A. The effect of retrobulbar injections of procaine on the optic nerve. Trans Ophthalmol Otolaryngol 1973; 77: 623-9.

11 Ropo A, Ruusuvaara P, Paloheimo M, Maunuksela E-L, Nikki P. Periocular anaesthesia: technique, effectivenes and complications with special reference to postoperative ptosis. Acta Ophthalmol (Kbh) 1990; 68: 728-32.

12 Levin ML, O'Connor PS. Visual acuity after retrobulbar anesthesia. Ann Ophthalmol 1989; 11 : 337-9.

13 Brent BD, Singh $\mathrm{H}$. The effect of retrobulbar anesthesia on visual acuity in planned extracapsular cataract extraction. Ophthalmic Surg 1991; 22: 392-5.

14 Russel DA, Guyton JS. Retrobulbar injection of lidocaine (Xylocaine) for anaesthesia and akinesia. Am $\mathcal{F}$ Ophthalmol

15 Ogden TE, Bassi CJ. New methods in clinical neurophysiology. In Wall M, Sadun AA, eds. New methods of sensory visual testing. New York: Springer-Verlag, 1989: 6893.
16 Weinstein GW. Clinical aspects of the visually evoked potential. Ophthalmic Surg 1978; 9: 56.

17 Raitta C, Karhunen U, Seppäläinen AM, Naukkarinen M Changes in the electroretinogram and visual evoked potentials during general anaesthesia. Graefes Arch Klin Exp Ophthalmol 1979; 211: 139-211.

18 Raitra C, Karhunen U, Seppäläinen AM Changes in electroretinogram and visual evoked potentials during general retinogram and visual evoked potentials during general anaesthesia using enflur.

19 Doden W, Bopp M. Opticusblockade durch retrobulbär Anästhesie. Klin Monatsbl Augenheilkb 1984; 184: 311-2.

20 Verma L, Arora R, Kumar A. Temporary conduction block of optic nerve after retrobulbar anesthesia. Ophthalmol Surg 1990; 21 : 109-12

21 Arora R, Verma L, Kumar A, Kunte R. Peribulbar anesthesia and optic nerve conduction. F Cat Refr Surg 1991; 17: 506-8.

(The visual evoked response. In: Heckenlively $\mathrm{JK}$, Arden $\mathrm{GB}$, eds. Principles and practice of clinical electrophysiology of vision. St Louis: Mosby, 1991: 17-22.

23 Harding GFA. Technical issues in visual evoked cortical potential recording. In: Heckenlively JR, Arden GB, eds. Principles and practice of clinical electrophysiology of vision. St Louis; Mosby, 1991: 435-41.

24 Ropo A, Nikki P, Ruusuvaara P, Kivisaari L. Comparison of retrobulbar and periocular injections of lignocaine using computerised tomography. BrF Ophthalmol 1991; 75: $417-$ 20.

25 Weiss JL, Diechmann CB. A comparison of retrobulbar and periocular anesthesia for cataract surgery. Arch Ophthalmol periocular anesthesia for cataract surgery. Arch Ophthalmo 26 Murdoch IE Peribul 1990; 4: 445-9. 